\title{
PENGURANGAN VOLUME SAMPAH DENGAN MEMANFAATKAN DAN MENDAUR ULANG SAMPAH MELALUI KEGIATAN PEMBUATAN PUPUK ORGANIK-KOMPOS
}

\author{
Uras Siahaan ${ }^{1}$, Sri Pare Eni ${ }^{2}$, Ulinata ${ }^{3}$ \\ Universitas Kristen Indonesia, Jakarta, Indonesia ${ }^{123}$ \\ urassiahaan@yahoo.com; sripareeni@yahoo.com; ulinnata@yahoo.com
}

\begin{abstract}
ABSTRAK
Permasalahan pengelolaan sampah telah menjadi permasalahan besar bagi kota-kota besar di Indonesia, termasuk kota DKI Jakarta. Untuk mengatasi hal ini, sumber penghasil sampah harus melakukan prinsip pemilahan dan life circle sampah yang berupa reduce (mengurangi), reuse (menggunakan ulang), dan recycle (mendaur ulang). Namun belum semua penduduk Jakarta melakukannya. UKI melalui program Pengabdian Pada Masyarakat telah melakukan kegiatan pembuatan pupuk organik-kompos di Kelurahan Cawang. Dalam rangka mengedukasi penduduk di Kelurahan Cawang maka UKI mengadakan program dengan menggunakan prinsip life circle sampah yang berupa reduce (mengurangi), reuse (menggunakan ulang), dan recycle (mendaur ulang) yaitu mendaur ulang sampah melalui kegiatan pembuatan pupuk organik-kompos. Program ini adalah program green action yang merupakan Program Pengabdian pada Masyarakat yang dilaksanakan Program Studi Arsitektur Fakultas Teknik Universitas Kristen Indonesia sejak mei 2009 dalam program penghijauan di kelurahan tersebut. Metode yang dilakukan adalah metode pendidikan masyarakat berupa penyuluhan, pelatihan (workshop) serta advokasi yang berupa pendampingan pada masyarakat kelurahan Cawang.Proses pembuatan kompos tersebut menggunakan tong komposter, cairan EM4 untuk mengelola sampah rumah tangga yang dipotong sehingga menghasilkan pupuk organik-kompos. Hasil yang diperoleh adalah berkurangnya volume sampah sehingga meningkatkan kualitas lingkungan, memperoleh edukasi mengenai pupukorganik kompos, meningkatkan hasil perekonomian dan dapat digunakan untuk tanaman sendiri.
\end{abstract}

Kata Kunci : Sampah, Kompos, Cawang

\section{ABSTRACT}

The problem of waste management has become a big problem for big cities in Indonesia, including the city of DKI Jakarta. To overcome this, a source of waste has to emphasize the sorting principle and waste life circle in the form of reduce, reuse, and recycle. Unfortunately, not all of the Jakarta Citizen do those principles. UKI through the Community Service program has carried out the activities of making compost-organic fertilizer in the Cawang Village. In order to educate residents in Cawang Sub-District, UKI held a program using waste life circle principles in the form of reduce, reuse and recycle waste through compost-making organic fertilizer. This program is a green action program which is a Community Service Program implemented by the Architecture Study Program of the Faculty of Engineering, Universitas Kristen Indonesia since May 2009 in a greening program in Cawang Village. The method used is the method of community education in the form of counseling, training (workshop) and advocacy in the form of assistance to the community of Cawang village. The process is using a cask composter and EM4 liquid to manage cut through domestic waste which is resulting in organic fertilizer - kompos. The result obtained is the decreasing in garbage volume and increasing in environment quality, having a knowledge about organic fertilizer, increasing the society economic condition and self using of organic fertilizer.

Key words : Garbage, Kompos, Cawang 


\section{PENDAHULUAN}

Salah satu persoalan besar yang dihadapi kota-kota besar di Indonesia adalah masalah pengelolaan sampah. Produksi sampah masyarakat modern tentu lebih banyak daripada penduduk tradisional. Masalah sampah berkaitan erat dengan pola hidup serta budaya penduduk itu sendiri dimana penanggulangan sampah bukan hanya urusan pemerintah saja, namun penanganannya membutuhkan partisipasi penduduk secara luas. Jumlah sampah ini setiap tahun terus meningkat sejalan dan seiring meningkatnya jumlah penduduk dan kualitas kehidupan penduduk dan akibat dari kemajuan ilmu pengetahuan teknologi yang menghasilkan pula pergeseran pola hidup penduduk yang cenderung konsumtif.

Pemerintah Provinsi DKI Jakarta belum dapat menangani sampah di ibu kota secara keseluruhan. Manajemen pengangkutan dan pengolahan sampah belum terbangun dengan baik, sementara produksi sampah juga belum bisa ditekan sehingga sampah masih terlihat berserakan di ruang-ruang publik. Dalam Undang-Undang Nomor 18 Tahun 2008 tentang Pengelolaan Sampah disebutkan bahwa sumber penghasil sampah sudah harus melakukan prinsip pemilahan dan life circle sampah yang berupa reduce (mengurangi), reuse (menggunakan ulang), dan recycle (mendaur ulang). Pengolahan yang umum digunakan di Indonesia adalah membawa sampah ke tempat pembuangan akhir, sedangkan sebagian kecil didaur ulang. Cara pengolahan dengan membawa sampah ke tempat pembuangan akhir masih bisa digunakan untuk daerah yang lahannya cukup luas, tetapi kurang efektif dikembangkan di daerah dengan luas lahan terbatas. Di sisi lain, penerapan pemilahan sampah mulai dari sumbernya masih minim dilakukan oleh penduduk, khususnya di kota-kota besar seperti Jakarta.

Salah satu provinsi yang memiliki masalah mengenai pengelolaan sampah adalah Jakarta Timur dimana Pemerintah Kota Administrasi Jakarta Timur hanya memiliki dua lokasi pembuangan sampah sementara di lokasi tersebut memproduksi 1.400 ton sampah per hari (http://www.tribunnews.com). Pemerintah Kota Administrasi Jakarta Timur memiliki beberapa kelurahan, salah satunya adalah kelurahan cawang. Cawang adalah sebuah kelurahan yang terletak di wilayah administrasi kecamatan Kramat Jati, Kota Administrasi Jakarta Timur. Kelurahan ini memiliki penduduk sebesar 39.126 jiwa dan luas 179.04 ha. Disebelah utara berbatasan dengan Jalan MT Haryono di sebelah utara, di sebelah barat berbatasan dengan Kali Ciliwung, di sebelah timur berbatasan dengan Jalan MayJend Sutoyo dan di sebelah selatan berbatasan dengan Jalan Makam Pahlawan Kalibata dan Jalan SMA Negeri 14. 
Usaha pengelolaan sampah menjadi pupuk organik-kompos sangat potensial untuk dikembangkan karena komposisi sampah di beberapa kota di Indonesia sangat besar (Damanhuri, 2006). Sumber sampah terbesar adalah domestik (pemukiman) maka usaha pengelolaan sampah menjadi pupuk organik-kompos semakin efisien apabila dilakukan sedekat mungkin dengan sumbernya dan skala kawasan misalnya kawasan pemukiman (RT/RW) dan kelurahan (Rahardyan, 1996).

Untuk meminimalisir volume sampah perlu dilakukan pengelolaan sampah melalui pemanfaatan sampah dan mendaur ulang sampah melalui kegiatan pembuatan pupuk organik-kompos di Kota Administrasi Jakarta Timur khususnya Kelurahan Cawang melalui program green action di tahun 2018. Program pengelolaan sampah melalui pemanfaatan sampah dan mendaur ulang sampah melalui kegiatan pembuatan pupuk organik-kompos diharapkan dapat memberikan manfaat dalam pengurangan volume sampah di Kota Administrasi Jakarta Timur khususnya di Kelurahan Cawang agar dapat meningkatkan kualitas lingkungan dan meningkatkan ekonomi penduduk.

\section{METODE}

Beberapa metode yang dipakai pada program pengurangan volume sampah dengan memanfaatkan sampah dan mendaur ulang sampah melalui kegiatan pembuatan pupuk organikkompos di Kelurahan Cawang kota administrasi Jakarta Timur adalah sebagai berikut:

\section{METODE PENDIDIKAN MASYARAKAT}

Metode pendidikan masyarakat dilakukan dengan cara penyuluhan yang bertujuan meningkatkan pemahaman serta kesadaran pada penduduk di Kelurahan Cawang khususnya di rw 06, rw. 10 dan rw.11. dalam program ini, penulis mengundang seorang narasumber bernama Bapak Sigit Priyana dimana beliau ini benar-benar ahli dalam bidang komposting.

Penyuluhan dari narasumber ini bertujuan untuk memberikan pembekalan materi kepada penduduk di Kelurahan Cawang khususnya di rw 06, rw. 10 dan rw.11 yang dapat mengedukasi penduduk tersebut mengenai komposting, sehingga pada waktu pelatihan atau workshop mereka dapat mempraktekkannya sendiri

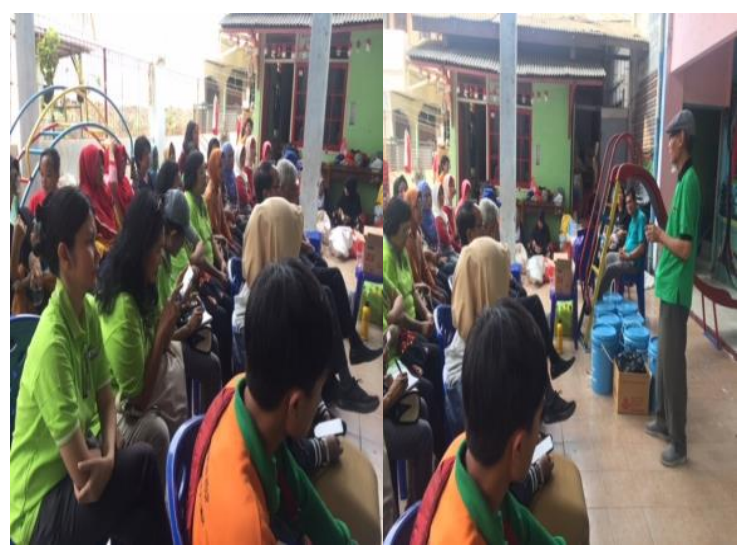

Gambar 1. Penyuluhan bersama Narasumber, Penulis dan Penduduk (Sumber : Penulis, 2018) 


\section{METODE PELATIHAN (WORKSHOP)}

Metode pelatihan (workshop) adalah kegiatan yang disertai dengan demonstrasi atau percontohan untuk menghasilkan keterampilan tertentu. Pada program Pengabdian pada Masyarakat ini, penulis melakukan pelatihan (workshop) di Kelurahan Cawang Provinsi Jakarta Timur melakukan workshop pada tanggal 1 oktober 2018 di kantor rw.06 yang dihadiri oleh panitia, penduduk rw 06, rw. 10 dan rw.11 Kelurahan Cawang, Provinsi Jakarta Timur, mahasiswa program studi arsitektur dan juga pembicara.

Adapun rangkaian kegiatan pelatihan (workshop) dari program pengabdian masyarakat ini adalah doa pembuka, kata sambutan, pembekalan materi atau penyuluhan dari narasumber, pembagian tong komposter dan EM4 pada penduduk rw 06, rw. 10 dan rw.11 (Gambar 2).

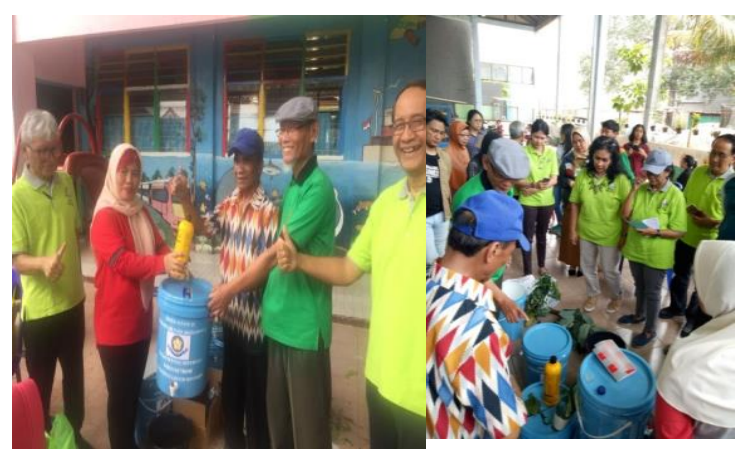

Gambar 2. Pelatihan (workshop) bersama

Narasumber, Penulis dan Penduduk

(Sumber : Penulis, 2018)

Setelah selesai diadakan pelatihan (workshop), narasumber dan penulis mengarahkan kepada penduduk di kelurahan cawang khususnya di penduduk rw 06, rw. 10 dan rw.11 untuk melakukan praktek sendiri dalam pembuatan pupuk organik-kompos dengan menggunakan tong komposter dan EM4 yang dipakai pada saat pelatihan (workshop) dan penulis akan melakukan pendampingan 3 (tiga) hari sekali dalam waktu sebulan untuk mendapatkan hasil yang diharapkan.

\section{METODE ADVOKASI}

Metode advokasi adalah kegiatan yang berupa pendampingan pada kelompok sasaran. Kelompok sasaran yang dimaksud adalah penduduk rw 06, rw. 10 dan rw.11 di Kelurahan Cawang.

Metode ini dilakukan penulis agar penduduk rw 06, rw. 10 dan rw.11 di Kelurahan Cawang memperoleh masukan terhadap permasalahan pada program kegiatan ini sehingga mendapatkan solusi dan hasil yang diharapkan yang sesuai dengan arahan dari penyuluhan yang telah diberikan oleh narasumber (Gambar $3)$.

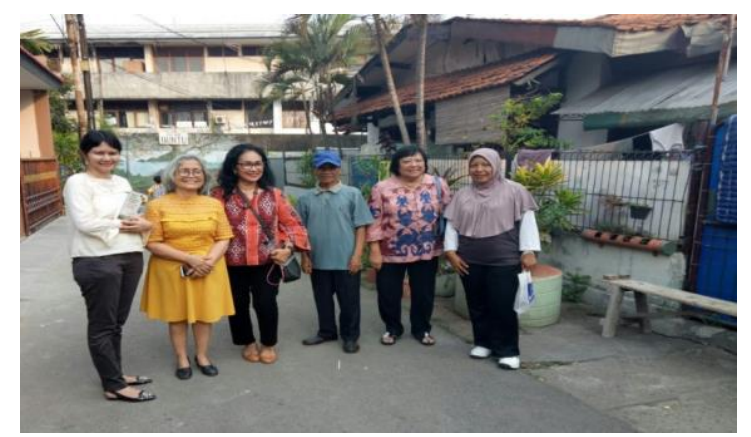

Gambar 3. Pendampingan bersama Penulis, Ketua RW 06 dan Penduduk RW 06 (Sumber : Penulis, 2018) 


\section{HASIL DAN PEMBAHASAN}

Program Green Action merupakan Program Pengabdian pada Masyarakat yang mulai dilaksanakan oleh Program Studi Arsitektur Fakultas Teknik Universitas Kristen Indonesia (UKI) sejak bulan mei 2009 dalam program penghijauan dan penyuluhan di Kelurahan Cawang, Jakarta Timur.

Program ini adalah kelanjutan dari program di tahun-tahun sebelumnya. Berikut adalah sebuah tabel program kegiatan pengabdian pada masyarakat yang dimulai dari tahun 2009 (Tabel 1)

Tabel 1. Program Kegiatan Pada Masyarakat Program Studi Arsitektur UKI

\begin{tabular}{|c|c|c|}
\hline No. & Nama Kegiatan & $\begin{array}{l}\text { Tahun } \\
\text { Kegiatan }\end{array}$ \\
\hline 1 & $\begin{array}{l}\text { Penyuluhan Kampung } \\
\text { Hijau Binaan UKI }\end{array}$ & $\begin{array}{l}2009- \\
2010\end{array}$ \\
\hline 2 & $\begin{array}{lr}\text { Sosialisasi, } & \text { Lomba } \\
\text { Kreasi } & \text { Hijau, } \\
\text { Penyuluhan } & \& \\
\text { Workshop } & \text { tentang } \\
\text { pengelolaan sampah, } \\
\text { Pengecatan Fasade } \\
\text { Dinding Unit } & \text { Rumah } \\
\text { Tinggal Pada Satu } \\
\text { Gang Yang Dipilih }\end{array}$ & $\begin{array}{l}2011- \\
2012\end{array}$ \\
\hline 3 & $\begin{array}{lr}\text { Pengelolaan } & \text { Sampah, } \\
\text { Evaluasi } & \text { Kondisi } \\
\text { Kawasan } & \text { Kelurahan } \\
\text { Cawang, Pengelolaan } \\
\text { Sistem } & \text { Operasional } \\
\text { Bank Sampah, Lomba } \\
\text { Kreasi } & \text { Linfgkungan }\end{array}$ & $\begin{array}{l}2013- \\
2014\end{array}$ \\
\hline
\end{tabular}

\begin{tabular}{|c|c|c|}
\hline & $\begin{array}{l}\text { Hijau dan Kreativitas } \\
\text { Daur Ulang dari } \\
\text { Sampah, Pengelolaan } \\
\text { Sampah Organik \& } \\
\text { Anorganik, } \\
\text { Sampah }\end{array}$ & \\
\hline 4 & 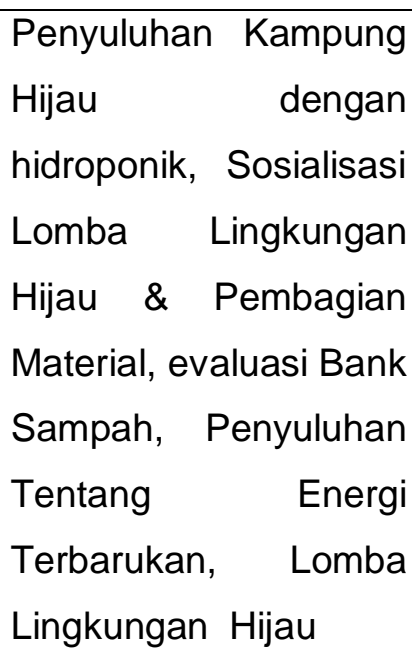 & $\begin{array}{l}2015- \\
2016\end{array}$ \\
\hline 5 & $\begin{array}{l}\text { Penyuluhan Kampung } \\
\text { Hijau, Komposting, } \\
\text { Hidroponik dan } \\
\text { Greenwall Painting }\end{array}$ & $\begin{array}{l}2017- \\
2018\end{array}$ \\
\hline
\end{tabular}

kelanjutan dari program sebelumnya dimana program Green Action ini memiliki beberapa program diantaranya adalah program pengurangan volume sampah dengan memanfaatkan sampah dan mendaur ulang sampah melalui kegiatan pembuatan pupuk organik-kompos di Kelurahan Cawang Provinsi Jakarta Timur.

Tiga cara yang cukup mudah dan aman untuk mengatasi permasalahan sampah adalah sebagai berikut :

1. Reduce (Mengurangi) yaitu tumpukan sampah organik yang berserakan di sekitar tempat tinggal yang diolah menjadi pupuk oragnik-kompos. 
2. Reuse (Penggunaan Kembali) yaitu barang yang dianggap sampah dari kegiatan pertama yang sebnarnya bisa berguna untuk kegiatan berikutnya baik untuk fungsi yang sama maupun berbeda. Misalnya komposter dapat dibuat dari bahan ayng diperoleh dari sekitar rumah misalnya drum, tong, ember atau kaleng cat yang dimodifikasi sedemikian rupa agar menjadi tong komposter. Tong Komposter bisa diberi alat pengaduk atau diaduk manual menggunakan tangan sendiri. Komposter diberi lubang udara agar membantu proses pengomposan aerob dengan baik dan mempercepat proses penguraian sampah. Selain itu komposter juga mampu menjaga kelembapan dan temperatur sehingga bakteri dan mikroorganisme dapat bekerja mengurai bahan organik secara optimal.

3. Recycle (Mendaur Ulang) yaitu usaha yang dilakukan dengan mengubah barang bekas menjadi benda lain yang lebih berguna dan layak pakai.

Untuk pembuatan kompos dari sampah organik digunakan bioaktivator effective microorganism (EM) yang berfungsi untuk memperbaiki struktur dan tekstur tanaman. EM dapat dibuat dengan menggunakan bahan yang mudah diperoleh namun sekarang sudah banyak dijual di toko kimia dan pertanian (Suryati, 2009). EM yang digunakan dalam pembuatan kompos dari sampah organik rumah tangga umumnya dalah EM4. Adapun tong komposter dan EM4 yang digunakan dalam program ini dapat dilihat pada gambar 4 di bawah ini.’

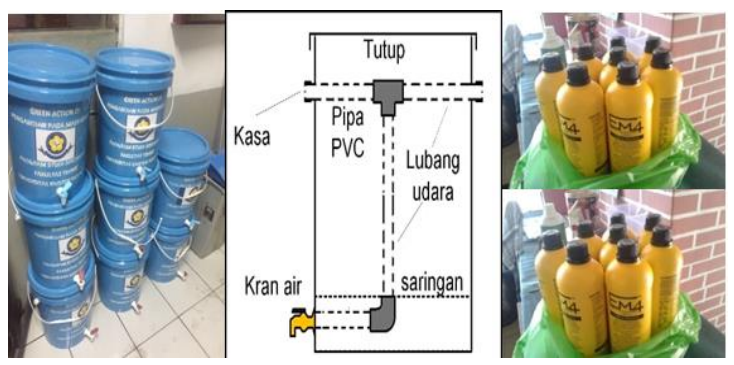

Gambar 4.Komposter dan EM4

(Sumber : Penulis, 2018)

Kegiatan pembuatan pupuk organik-kompos di Kelurahan Cawang, provinsi Jakarta Timur di beberapa rw diantaranya rw 06, rw 10, rw 11 . Sebelum dilaksanakan program kegiatan ini, Program Studi Arsitektur Fakultas Teknik Universitas Kristen Indonesia (UKI) membentuk panitia program kegiatan Pengabdian Pada Masyarakat (terlihat pada lampiran). Kemudian dilaksanakan sosialisasi Program Green Action merupakan Program Pengabdian pada Masyarakat oleh Program Studi Arsitektur Fakultas Teknik Universitas Kristen Indonesia (UKI) diawali dengan sosialisasi yang diadakan di Ruang Studio Fakultas Teknik yang dihadiri oleh perwakilan warga di rw 06, rw. 10 dan rw.11 beserta penulis dan narasumber pada tanggal 22 September 2018 (Gambar 5). 


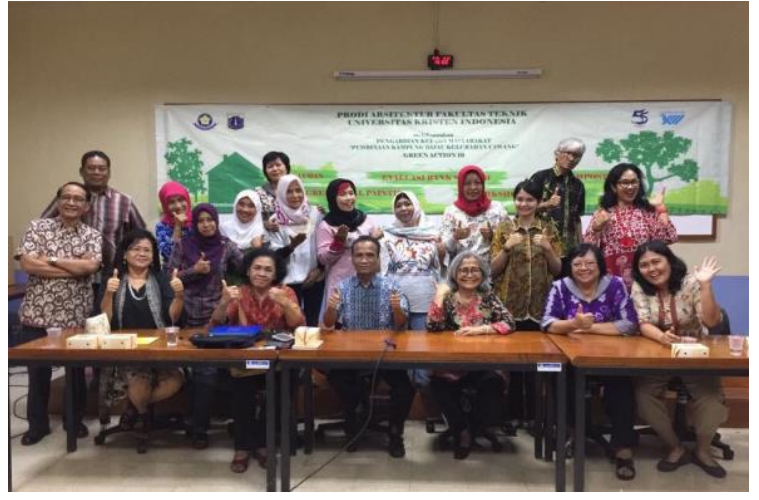

Gambar 5 Sosialisasi Program Pengabdian pada Masyarakat

(Sumber : Penulis, 2018)

Setelah sosialisasi diadakan pelatihan (workshop), narasumber dan penduduk kelurahan cawang khususnya penduduk rw.06, rw.10, rw.11 sehingga mereka dapat melakukan praktek sendiri untuk pembuatan pupuk organik-kompos dengan menggunakan tong komposter dan EM4 yang dipakai pada saat pelatihan (workshop).

Cara pembuatannya dilakukan dengan beberapa tahap sebagai berikut :

1. Mengumpulkan sisa-sisa sampah rumah tangga berupa sayuran dan dedaunan yang kemudian dipotong kecil-kecil menggunakan gunting yang kemudian dimasukkan ke dalam tong komposter. Setelah sisa-sisa sampah rumah tangga berupa sayuran dan dedaunan yang dipotong kecil-kecil dimasukkan ke dalam tong komposter, lalu dimasukkan cairan berupa EM4 secukupnya yang kemudian diaduk rata yang kemudian ditutup selama 3 hari (Gambar 6).

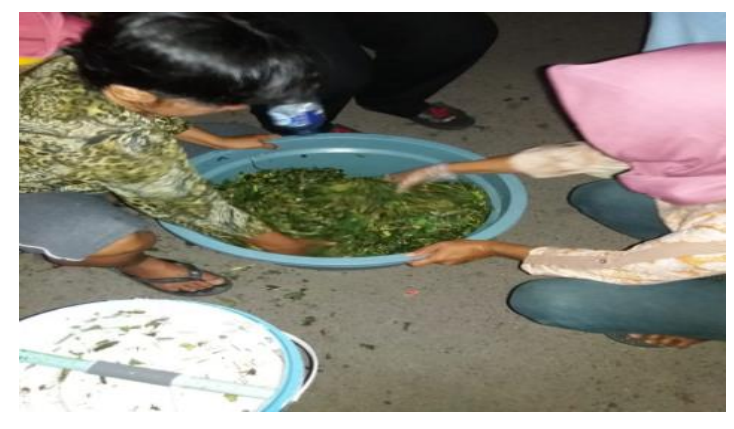

Gambar 6. Proses Pengadukan

(Sumber : Penulis, 2018)

2. Agar mengalami peningkatan hasil pengadukan di hari berikutnya disiram cairan EM4 yang lebih kental dari sebelumnya. Perbandingan EM4 : gula pasir $:$ air = 1:1:40/50 diganti dengan 2:2:40. Setelah 30 hari, kompos yang terdapat pada tong komposter teksturnya yang masih basah akan dikeringkan dengan cara dijemur dan setelah kompos kering kemudian dilakukan penyaringan. Kompos yang yang telah mengalami proses penyaringan, dimasukkan ke dalam plastik (kemasan) kemudian dijual atau dimanfaatkan sendiri oleh penduduknya untuk menyuburkan tanamannya. Hasil penjualan dapat meningkatkan ekonomi penduduk RT/RW di Kelurahan Cawang (Gambar 7). 


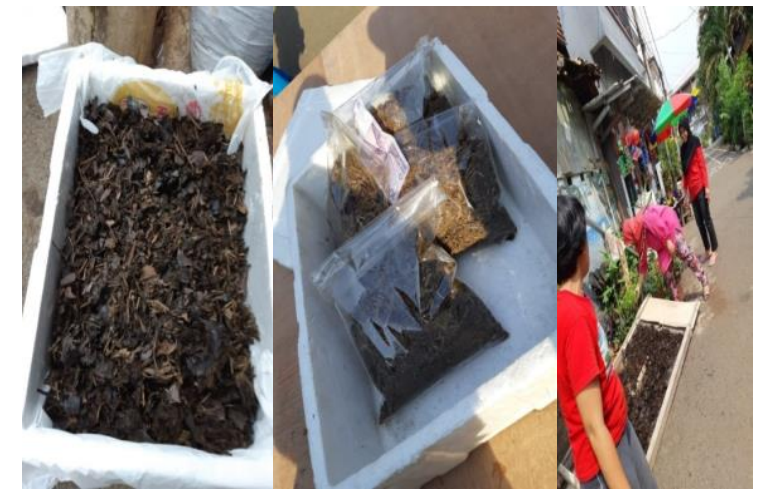

Gambar 7. Proses Penjemuran Pupuk

Organik-Kompos

(Sumber : Penulis, 2018)

Penduduk yang melakukan pengadukan dan memiliki hasil kompos yang dikemas dalam plastik membuat stand di sekitar rumahnya untuk menjual kompos tersebut. Terdapat aktivitas penjual dan pembeli kompos pada gambar 8.

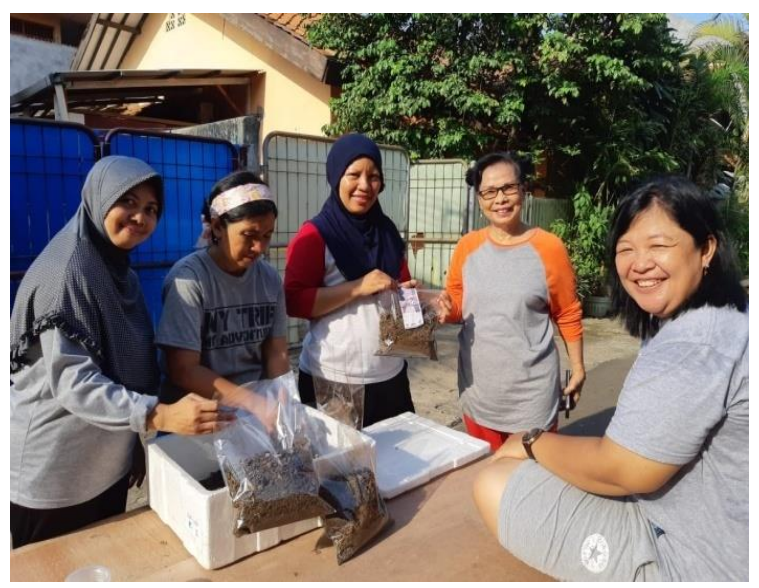

Gambar 8. Penjual dan Pembeli Pupuk Organik-Kompos

(Sumber : Penulis, 2018)

\section{SIMPULAN}

Program Pengabdian Masyarakat yang berjudul Pengurangan Volume Sampah dengan Memanfaatkan dan Mendaur Ulang Sampah Melalui Kegiatan
Pembuatan Pupuk Organik-Kompos telah terlaksana dengan baik pada tahun 2018 di beberapa RT/RW Kelurahan Cawang.

Program ini terdiri dari beberapa rangkaian acara diantaranya proses sosialisasi, workshop, pembagian tong komposter dan cairan EM4 serta peninjauan progress bagi penduduk yang ingin mempraktikkan sendiri di rumahnya. Penduduk sangat antusias dan merasa program ini sangat bermanfaat karena dengan mendapat edukasi yang cukup mengenai pupuk-organik kompos juga dapat meningkatkan hasil perekonomian dari hasil pupuk organik-kompos yang telah mereka buat dan dapat menggunakan pupuk organik-kompos yang mereka buat untuk tanaman mereka sendiri.

Semoga Program Pengabdian Masyarakat yang berjudul Pengurangan Volume Sampah dengan Memanfaatkan dan Mendaur Ulang Sampah Melalui Kegiatan Pembuatan Pupuk OrganikKompos dapat berkelanjutan di tahuntahun berikutnya.

\section{UCAPAN TERIMA KASIH}

Puji dan syukur kami panjatkan ke hadirat Tuhan Yang Maha Esa, karena berkat rahmat dan karunia-Nya kami dapat menyelesaikan seluruh proses penyusunan Laporan Program Pengabdian Pada Masyarakat Program Studi Arsitektur Fakultas Teknik UKI di tahun 2018 ini yang berjudul Pengurangan Volume Sampah dengan Memanfaatkan 
dan Mendaur Ulang Sampah Melalui Kegiatan Pembuatan Pupuk OrganikKompos sebagai salah satu Program Green Action yang dilaksanakan sejak bulan mei 2009.

Terimakasih sebesar-besarnya tidak lupa kami ucapkan ucapkan kepada :

1. Universitas Kristen Indonesia sebagai sumber dana dari Program Pengabdian Pada Masyarakat yang berjudul Pengurangan Volume Sampah dengan Memanfaatkan dan Mendaur Ulang Sampah Melalui Kegiatan Pembuatan Pupuk Organik-Kompos.

2. Bapak Dr. Dhaniswara K. Harjono, SH., MH., MBA, sebagai Rektor Universitas Kristen Indonesia.

3. Bapak Haerudin, SH selaku Lurah di Kelurahan Cawang yang telah memberikan dukungan demi kelancaran kegiatan Program Pengabdian Pada Masyarakat ini.

4. Bapak Sigit Priyana yang telah menjadi narasumber dalam Program Pengabdian Pada Masyarakat ini.

5. Ibu Ir.Galuh Widati, M.Sc, sebagai Dekan Fakultas Teknik Universitas Kristen Indonesia.

6. Bapak Ir.Sahala Simatupang, MT, sebagai Ketua Program Studi Arsitektur Universitas Kristen Indonesia.

7. Ibu Prof.Dr.Ing.Ir.Uras Siahaan, Lic.rer.reg, lbu Prof.Dr.Ing.Ir.Sri Pare Eni, Lic.rer.reg dan Ibu Ulinata, ST.Ars., MT selaku pelaku kegiatan dan team penulis.. Terimakasih atas kerjasamanya.

8. Rekan Dosen Program Studi Arsitektur Fakultas Teknik UKI yang berpartisipasi untuk mendukung Program ini agar dapat berjalan lancar dan sukses.

9. Ketua rw 06, rw. 10 dan rw.11 serta penduduk rw 06, rw. 10 dan rw.11 di Kelurahan Cawang, Kota Administrasi Jakarta Timur yang sudah meluangkan waktu dan tenaganya untuk mengikuti Program ini.

10. Para mahasiswa UKI, serta semua pihak yang tidak dapat disebutkan satu per satu karena telah berpartisipasi untuk mensukseskan Program ini.

Semoga artikel ini dapat bermanfaat bagi kita semua khususnya di lingkungan Program Studi Arsitektur Fakultas Teknik UKI.

\section{REFERENSI}

Damanhuri, E dan Padmi. T. 2006. Pengelolaan Sampah. Diktat Kuliah Dep. Teknik Lingkungan ITB. Bandung.

Rahardiyan B. dan Murdeani. D. A. 2006. Sikap Masyarakat Terhadap Pemilahan Sampah Berbasis Pengumpulan Terjadwal. Jurnal Infrastruktur dan Lingkungan Binaan Vol. II. No. 2 Desember 2006.

Suryati, T. 2009. Bijak \& Cerdas Mengolah Sampah Membuat Kompos dari 
Volume 1, Nomor 1, Tahun 2019 Hal 1 -10

Sampah Rumah Tangga. Jakarta:

Pt.Agromedia Pustaka

Undang-Undang Nomor 18 Tahun 2008

tentang Pengelolaan Sampah

http://www.tribunnews.com 